\title{
Erratum to: "Structure and Properties of Superhard Materials Based on Aluminum Dodecaboride $\alpha-\mathrm{AlB}_{12}$ " [Journal of Superhard Materials, vol. 39, no. 5, pp. 299-307, 2017]
}

\author{
T. A. Prikhna ${ }^{a}{ }^{*}$, P. P. Barvitskyi ${ }^{a}$, M. B. Karpets ${ }^{b}$, V. B. Muratov ${ }^{b}$, V. B. Sverdun ${ }^{a}$, P. Khaber ${ }^{c}$, \\ V. V. Kartuzov ${ }^{b}$, V. E. Moshchil ${ }^{a}$, S. N. Dub ${ }^{a}$, M. G. Loshak ${ }^{a}$, L. I. Aleksandrova ${ }^{a}$, \\ V. V. Kovylyaev ${ }^{d}$, V. V. Garbuz ${ }^{b}$, and A. A. Marchenko ${ }^{a}$ \\ ${ }^{a}$ Bakul Institute of Superhard Materials, \\ National Academy of Sciences of Ukraine, \\ vul. Avtozavods'ka 2, 04074, Kiev, Ukraine \\ ${ }^{b}$ Frantsevich Institute of the Materials Problems, \\ National Academy of Sciences of Ukraine, Kiev, Ukraine \\ ${ }^{c}$ Rutger University, New-Branswik, USA \\ ${ }^{d}$ Proton-21 (LEI), Research laboratory of electrodynamic researches, Vishnevoe, Ukraine \\ *e-mail:prikhna@mail.ru,prikhna@ukr.net
}

Received August 26, 2016

DOI: $10.3103 / \mathrm{S} 1063457617060089$

We would like to inform you that a sad mistake was made in one of our articles in "Journal of Superhaed Materials", 2017, vol. 39, no. 5, pp. 299-307. The article is "Structure and Properties of Superhard Materials Based on Aluminum Dodecaboride $\alpha-\mathrm{AlB}_{12}$ ” by T. A. Prikhna, P. P. Barvitskyi, M. B. Karpets, V. B. Muratov, V. B. Sverdun, P. Khaber, V. V. Kartuzov, V. E. Moshchil', S. N. Dub, M. G. Loshak, L. I. Aleksandrova, V. V. Kovylyaev, V. V. Garbuz, and A. A. Marchenko.

Thus, the author's name P. Khaber should be replaced by R. Haber.

Then the authors of the article are:

T. A. Prikhna ${ }^{a}{ }^{*}$, P. P. Barvitskyi ${ }^{a}$, M. B. Karpets ${ }^{b}$, V. B. Muratov ${ }^{b}$, V. B. Sverdun ${ }^{a}$, R. Haber ${ }^{c}$, V. V. Kartuzov ${ }^{b}$, V. E. Moshchil' ${ }^{\prime}$, S. N. Dub ${ }^{a}$, M. G. Loshak ${ }^{a}$, L. I. Aleksandrova ${ }^{a}$, V. V. Kovylyaev ${ }^{d}$, V. V. Garbuz ${ }^{b}$, and A. A. Marchenko ${ }^{a}$

${ }^{a}$ Bakul Institute of Superhard Materials,

National Academy of Sciences of Ukraine,

vul. Avtozavods'ka 2, 04074, Kiev, Ukraine

${ }^{b}$ Frantsevich Institute of the Materials Problems,

National Academy of Sciences of Ukraine, Kiev, Ukraine

${ }^{c}$ Rutger University, New-Branswik, USA

dProton-21 (LEI), Research laboratory of electrodynamic researches, Vishnevoe, Ukraine

*e-mail:prikhna@mail.ru,prikhna@ukr.net

Received August 26, 2016 